\title{
Mikrostruktura i właściwości natryskiwanych naddźwiękowo powłok WC-12Co po obróbce elektroiskrowej
}

\section{Microstructure and properties of supersonically sprayed WC-12Co coatings after electro-spark deposition process}

\section{Streszczenie}

W artykule przedstawiono wyniki badań natryskiwanych naddźwiękowo nanostrukturalnych i konwencjonalnych powłok WC-12Co po obróbce elektroiskrowej (ESD) elektrodą z węglika wolframu. Analiza zmian mikrostruktury i właściwości powłok została przeprowadzona przy użyciu mikroskopu skaningowego Joel JSM-5400. Do określenia zmian rozkładu pierwiastków zastosowano mikrosondę ISIS 300 Oxford Instruments, a zmiany składu fazowego zostały zbadane dyfraktometrem D8 Advance (Bruker). Stwierdzono, że na powierzchniach nałożonych powłok po obróbce ESD została utworzona homogeniczna powłoka z niską zawartością kobaltu o bardzo dobrej przyczepności, a wysoka temperatura procesu spowodowała zmiany fazowe w powłoce. Obydwie natryskiwane powłoki WC-12Co po obróbce elektroiskrowej miały podobną twardość, chropowatość oraz współczynnik tarcia, a powłoka nanostrukturalna WC-12Co wykazała większą odporność na zużycie ścierne.

\section{Abstract}

The paper concerns properties of HVOF sprayed two tungsten carbide coatings after applying electro-spark deposition process (ESD). After finishing microstructure of sprayed coatings were changed by applying tungsten carbide electrode. Analysis of changes in microstructure and properties of the coatings was performed using scanning electron microscope Joel JSM-5400. To determine the changes in the distribution of elements was used microprobe ISIS 300 Oxford Instruments and the changes of phase composition were examined by D8 Advance (Bruker) diffractometer. It was found that on the surfaces of sprayed coatings after ESD process was formed a homogeneous layer with a low content of cobalt and very good adhesion. The high temperature of the process caused changes in phase composition of sprayed coating. Both sprayed WC-12Co coating after ESD process have similar hardness, roughness and coefficient of friction. The nanostructured WC-12Co coating showed higher resistance to abrasive wear.

\section{Wstęp}

Węglik wolframu charakteryzuje się wysoką twardością oraz odpornością na pękanie. Właściwości te spowodowały, że znalazł szerokie zastosowanie w różnych gałęziach przemysłu, przede wszystkim na narzędzia skrawające oraz części maszyn o bardzo wysokiej odporności na zużycie w postaci spieków.

Dr inż. Wojciech Żórawski, dr inż. Norbert Radek - Politechnika Świętokrzyska, Kielce.
Nowe możliwości wykorzystania doskonałych właściwości węglika wolframu umożliwiło wprowadzenie w latach 50 . XX w. procesu natryskiwania plazmowego, co pozwoliło na zastosowanie tego materiału w postaci powłoki cermetalowej składającej się z ziaren węglika wolframu osadzonych w kobaltowej matrycy. Jednak wysoka temperatura strumienia plazmy i obecność tlenu prowadziły do zmian fazowych w natryskiwanym proszku, co w konsekwencji powodowało znaczne pogorszenie właściwości powłok, zwłaszcza w porównaniu z materiałami spiekanymi [1]. Znacznie lepsze właściwości miały powłoki natryskiwane detonacyjnie wprowadzone już w połowie 
lat 50., jednak metoda ta została opatentowana i ze względów komercyjnych nie została rozpowszechniona. Znaczny postęp nastąpił w połowie lat 80 ., kiedy Jim Browning opracował nowy proces natryskiwania naddźwiękowego HVOF, który umożliwił otrzymywanie powłok $z$ węglika wolframu o bardzo wysokiej jakości [2, 3]. Pozwoliło to na znaczne rozszerzenie zastosowań tych powłok. Ich bardzo wysoka odporność na zużycie i korozję pozwala w wielu przypadkach na eliminację powłok chromowych nakładanych galwaniczne, których proces wytwarzania wiąże się z powstawaniem kancerogennego chromu sześciowartościowego.

Jednocześnie rozwój nanotechnologii spowodował intensyfikację badań nad wykorzystaniem nanomateriałów w procesach natryskiwania cieplnego, co umożliwiło otrzymywanie nowej klasy powłok o budowie nanostrukturalnej i lepszych właściwościach.

Mimo ogromnego postępu w zakresie zastosowania powłok natryskiwanych cieplnie, a w szczególności natryskiwania plazmowego i naddźwiękowego, nadal prowadzone są badania nad polepszeniem ich właściwości. Wiąże się to przede wszystkim z eliminacją porowatości, ograniczeniem zmian fazowych, zwiększeniem wytrzymałości, a przede wszystkim modyfikacją warstwy wierzchniej. Można ją uzyskać w wyniku uszczelniania powłok, stosowania różnych dodatków, obróbki cieplnej lub zastosowania jednej z metod inżynierii powierzchni.

Metody te są stosowane również do poprawy właściwości powłok natryskiwanych z węglika wolframu. Elektrolityczna impregnacja powłoki miedzią poprawiła jej właściwości trybologiczne [4]. Dodatek $6 \%$ ETFE do natryskiwanego proszku obniżył współczynnik tarcia natryskiwanej naddźwiękowo powłoki WC-12Co [5]. Obróbka cieplna nanostrukturalnych powłok WC-Co zwiększyła ich twardość i poprawiła o $45 \%$ odporność na zużycie ścierne $[6,7]$. Jednak zastosowanie procesu borowania do powłok z węglika wolframu spowodowało obniżenie twardości powłoki WC-12Co i nie polepszyło jej właściwości [1]. Nowe możliwości podwyższenia właściwości powłok WC-Co stwarza obróbka elektroiskrowa (Elektrospark Deposition - ESD). Umożliwia ona nakładanie na wybranych powierzchniach powłok z różanych materiałów o grubości od kilku do kilkudziesięciu mikrometrów.

Dodatkową zaletą tego procesu jest bardzo wysoka adhezja nałożonych powłok do podłoża. Procesy obróbki elektroerozyjnej związane są z przepływem masy i energii, którym towarzyszą reakcje chemiczne i elektrochemiczne. W czasie procesu nakładania powłok występuje lokalnie bardzo wysoka temperatura sięgająca $(5 \div 40) 10^{3} \mathrm{~K}$ oraz bardzo wysoka ciśnienie rzędu $(2 \div 7) 10^{3}$ GPa. W przeprowadzonej pracy zastosowano obróbkę elektroiskrową ESD do poprawy właściwości natryskiwanych naddźwiękowo powłok nanostrukturalnych i konwencjonalnych z węglika wolframu.

\section{Metodyka badań}

Dwie powłoki natryskiwane z nanostrukturalnego i konwencjonalnego proszku WC-12Co zostały poddane procesowi obróbki elektroiskrowej. Na rysunku 1a i 2a pokazano wielkość i morfologię ziaren obydwu natryskiwanych proszków; nanostrukturalnego (Infralloy S7412) oraz konwencjonalnego (Amperit 519.074). Są to materiały przeznaczone specjalnie do natryskiwania cieplnego, otrzymywane w wyniku aglomeracji oraz spiekania drobnych ziaren proszku. Mają one bardzo duży udział ziaren o kształcie sferoidalnym, co znacznie zwiększa ich sypkość w porównaniu z proszkami o nieregularnym kształcie ziarna. Na wykonanym zgładzie metalograficznym ziaren proszku widoczna jest ich budowa (rys. 1b i 2b). Ziarna są porowate, co jest wynikiem procesu ich wytwarzania. Przeprowadzone badania (SEM) struktury ziaren proszku WC-12Co-N wykazały, że w ich skład wchodzą nanokryształy (rys. 3).

Do natryskiwania powłok zastosowano system natryskiwania naddźwiękowego Hybrid Diamond Jet HVOLF, w którym do procesu natryskiwania jako
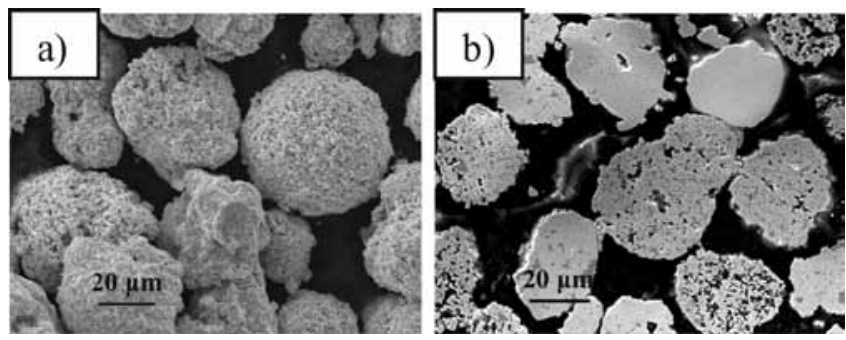

Rys. 1. Nanostrukturalny proszek WC-12Co: a) ziarna proszku, b) przekrój ziaren proszku

Fig. 1. Nanostructured WC-12Co powder: a) powder particles, b) cross-section of the particles
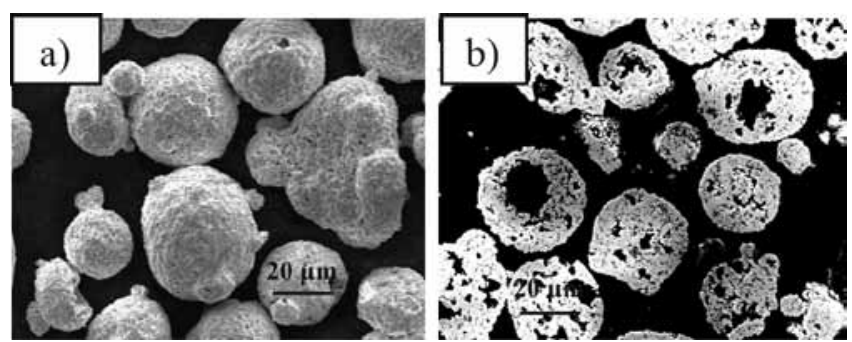

Rys. 2. Konwencjonalny proszek WC-12Co: a) ziarna proszku, b) przekrój ziaren proszku

Fig. 2. Conventional WC-12Co powder: a) powder particles, b) cross-section of the particles

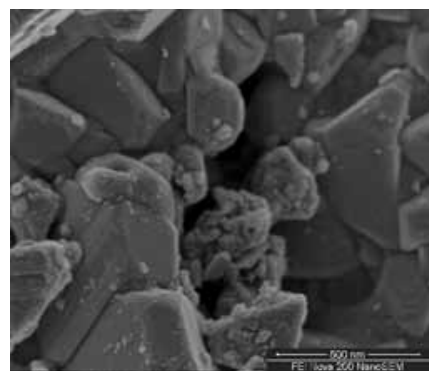

Rys. 3. Morfologia nanostrukturalnego ziarna proszku WC-12Co

Fig. 3. Morphology of nanostructured WC-12Co powder particles 
paliwo została zastosowana mieszanina propanu i tlenu. Zastosowano następujące parametry natryskiwania: ciśnienie propanu - 0,69 MPa, natężenie przepływu propanu - $77 \mathrm{NI} / \mathrm{min}$, ciśnienie tlenu - 1,03 MPa, natężenie przepływu tlenu - $252 \mathrm{NI} / \mathrm{min}$, ciśnienie powietrza - 0,72 MPa, natężenie przepływu powietrza $-375 \mathrm{NI} / \mathrm{min}$, odległość natryskiwania $-200 \mathrm{~mm}$.

Do badania struktury i składu chemicznego proszków i powłok zastosowano mikroskopy skaningowe: JSM-5400 z mikrosondą ISIS 300 Oxford (EDS) oraz FEI Company Novaä NanoSEM 200. Badania składu fazowego prowadzono na dyfraktometrze D8 Advance (Bruker). W badaniach zastosowano filtrowane promieniowanie serii $\mathrm{Ka}$, anody Co o długości fali $\lambda=1,78897 \cdot 10^{-10} \mathrm{~m}$.

Do badań metalograficznych stosowano próbki ze stali węglowej wyższej jakości C45 o wymiarach $50 \times 25 \times 5 \mathrm{~mm}$ z powłokami węglikowymi natryskiwanymi naddźwiękowo przed i po modyfikacji EDM. Natomiast do badań trybologicznych stosowano pierścienie ze stali C45 o wymiarach ø46xø25x6 mm z powłokami WC-12Co oraz WC-17Co natryskiwanymi naddźwiękowo przed i po modyfikacji EDM. Przed procesem próbki ze stali C45 zostały poddane obróbce strumieniowo-ściernej elektrokorundem 12EB przy ciśnieniu 0,5 MPa. Średnia grubość nałożonych powłok po szlifowaniu wynosiła ok. 0,3 $\div 0,4 \mathrm{~mm}$.

Modyfikację elektroerozyjną powierzchni obydwu powłok WC-12Co przeprowadzono elektrodą WC8Co na urządzeniu EIL-8A z zastosowaniem następujących parametrów: napięcie $\mathrm{U}=230 \mathrm{~V}$, pojemność kondensatorów $C=150 \mu \mathrm{m}$, natężenie prądu $\mathrm{I}=2,4 \mathrm{~A}$.

Pomiary mikrotwardości wykonano metodą Vickersa przy użyciu mikrotwardościomierza Matuzawa MMT-X3A, stosując obciążenie 100 G i 5 G. Wykonano 15 pomiarów (dla każdej powłoki), a następnie obliczono wartość średnią z tych pomiarów. Mikrotwardość powłoki WC-12Co wyniosła 1147 HV0,1, natomiast powłoki WC-17Co $1640 \mathrm{HV0}, 1$.

Do pomiaru chropowatości powierzchni wykorzystano przyrząd Talysurf $4 \mathrm{z}$ programem SUFORM, który znajduje się w Laboratorium Komputerowych Pomiarów Wielkości Geometrycznych Katedry Technologii Mechanicznych i Metrologii PŚk. Wykonano 10 pomiarów (dla każdej powłoki), a następnie obliczono wartość średnią z tych pomiarów.

Badania tribologiczne powłok zostały wykonane na testerze tribologicznym T-01M typu kulka-pierścień. Przeciwpróbką była kulka o średnicy $\varnothing 6,35 \mathrm{~mm}$ (1/4") wykonana ze stali $100 \mathrm{Cr} 6$. Badania na testerze przeprowadzono przy następujących parametrach tarcia: obciążenie 4,9 $\mathrm{N}$, prędkość liniowa $\mathrm{V}=1 \mathrm{~m} / \mathrm{s}$, czas próby $\mathrm{t}=3600 \mathrm{~s}$. Do określenia odporności na zużycie ścierne natryśniętych powłok po obróbce ESD zastosowano tester tribologiczny T-07 (dry sand-rubber wheel machine).

\section{Wyniki badań i dyskusja}

Przed nałożeniem powłok elektroiskrowych obydwie natryśnięte naddźwiękowo powłoki WC-12Co były szlifowane (rys. 4a i 5a). Widoczna jest znikoma ilość niewielkich porów oraz równoległe rysy będące wynikiem obróbki szlifierskiej. Chropowatość powierzchni Ra wynosiła odpowiednio 0,034 i 0,054 mm dla powłoki nanostrukturalnej i konwencjonalnej, a mikrotwardość odpowiednio 1131,7士83 i $984,2 \pm 68$ HV0,1. Mikrostruktura tych powierzchni uległa zmianie po obróbce elektroiskrowej elektrodą WC8Co, tzn. nałożeniu warstwy elektroiskrowej (rys. 4). Pomimo że parametry obróbki były takie same dla obydwu powłok, to w powłoce nanostrukturalnej pojawiła się duża ilość okrągłych porów. Powierzchnie po obróbce elektroiskrowej są gładkie, ale można na nich zaobserwować niewielkie pęknięcia. Chropowatość powłok wyniosła odpowiednio 1,93 i 2,33 mm dla powłoki nanostrukturalnej i konwencjonalnej, a mikro-

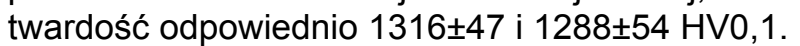

$\mathrm{Na}$ rysunku $6 \mathrm{a}$ i $6 \mathrm{~b}$ przedstawiono mikrostruktury obydwu powłok - nanostrukturalnej i konwencjonalnej WC-12Co z nałożoną elektroiskrowo warstwą z zastosowaniem elektrody WC8Co. Grubość warstw uzyskanych w wyniku obróbki ESD wyniosła $7 \div 9 \mu \mathrm{m}$. Widoczna jest wyraźna różnica w budowie mikrostruktury natryskiwanych naddźwiękowo powłok
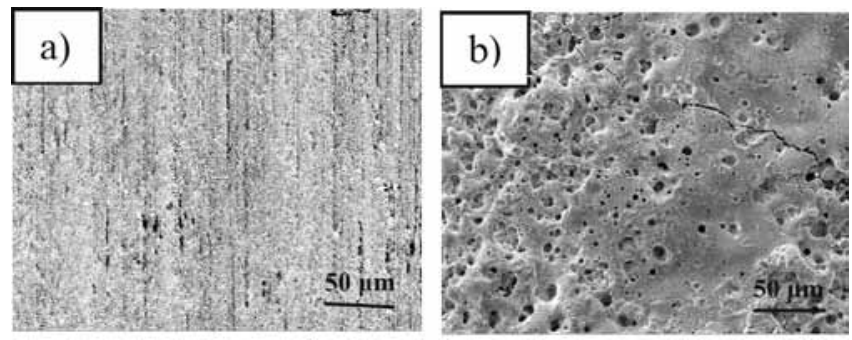

Rys. 4. Mikrostruktura powierzchni: a) natryskiwanej nanostrukturalnej powłoki WC-12Co po szlifowaniu, b) po nałożeniu warstwy elektroiskrowej

Fig. 4. Surface microstructure: a) sprayed nanostrustured WC-12Co coating after grinding, b) after electro-spark discharge deposited layer
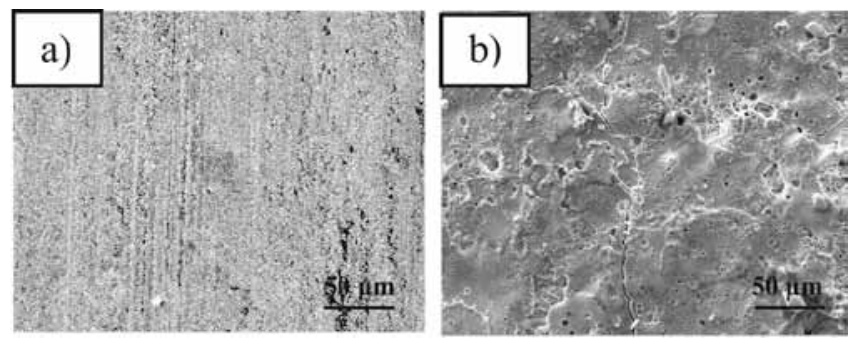

Rys. 5. Mikrostruktura powierzchni: a) natryskiwanej konwencjonalnej powłoki WC-12Co po szlifowaniu, b) po nałożeniu warstwy elektroiskrowej

Fig. 5. Surface microstructure: a) sprayed conventional WC-12Co coating after grinding, b) after electro-spark discharge deposited layer 

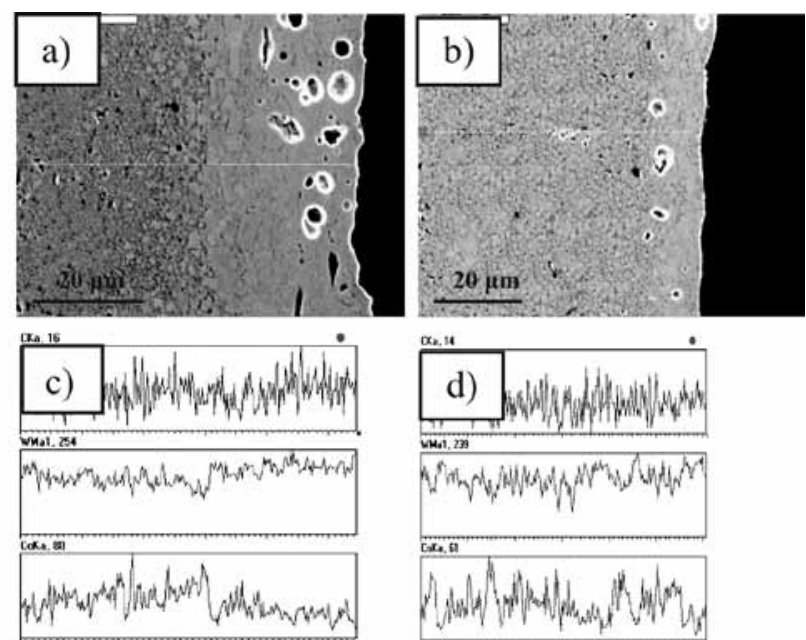

Rys. 6. Mikrostruktura: a) natryśniętej nanostrukturalnej powłoki WC-12Co po obróbce ESD, b) natryśniętej konwencjonalnej powłoki WC-12Co po obróbce ESD, c, d) rozkład liniowy

Fig. 6. Surface microstructure a) sprayed nanostrustured WC-12Co coating after ESD manufacturing, b) sprayed conventional WC-12Co coating after ESD machining, c) EDS analysis

oraz naniesionej elektroiskrowo warstwy. $\mathrm{Na}$ obydwu zgładach nałożonych powłok widoczne są drobne jasne nieodkształcone ziarna, które są osadzone w ciemnej matrycy (rys. 6a i 6b). Przeprowadzona analiza liniowa pokazała nierównomierny rozkład pierwiastków w powłoce natryskiwanej naddźwiękowo (rys. 6c i 6d). Można wyróżnić strefy, w których występuje znaczne zróżnicowanie ilości wolframu i kobaltu. $\mathrm{Na}$ tej podstawie można stwierdzić, że w nałożonych powłokach jasna faza o dużej zawartości wolframu to ziarna węglika wolframu, natomiast ciemna matryca to obszar bogaty w kobalt z niedużą zawartością wolframu. W obydwu powłokach widoczna jest niewielka porowatość. Nałożona elektroiskrowo na powłoki warstwa w obydwo przypadkach ma jednorodną budowę z niewielką ilością okrągłych porów, która jest większa w przypadku warstwy naniesionej na nanostrukturalną powłokę WC-12Co (rys. 6a i 6b).

Analizy liniowe warstw pokazują wyższą zawartość wolframu, niższą zawartość kobaltu oraz ich bardziej równomierny rozkład $w$ nałożonej elektroiskrowo powłoce niż w przypadku powłok natryskiwanych (rys. 6c i 6d). Jest to wynikiem niższej zawartości kobaltu $(8 \%)$ w elektrodzie zastosowanej do nałożenia warstwy elektroiskrowej. Stopniowa zmiana zawartości W i Co przy przejściu z powłoki do warstwy świadczy o jej bardzo dobrym połączeniu z powłoką.

Przeprowadzone badania dyfraktometryczne umożliwiły zidentyfikowanie składu fazowego powłok przed obróbką (rys. 4a i 5a) i po obróbce elektroiskrowej (rys. $4 \mathrm{~b}$ i $5 \mathrm{~b}$ ). Na podstawie analizy dyfraktogramów natryskiwanych powłok można stwierdzić wysoką intensywność pików WC, który był głównym składnikiem natryskiwanych proszków [8]. Obecne na dyfraktogramach małe piki wolframu są wynikiem wpływu temperatury naddźwiękowego strumienia na natryskiwany proszek, co spowodowało dekompozycję

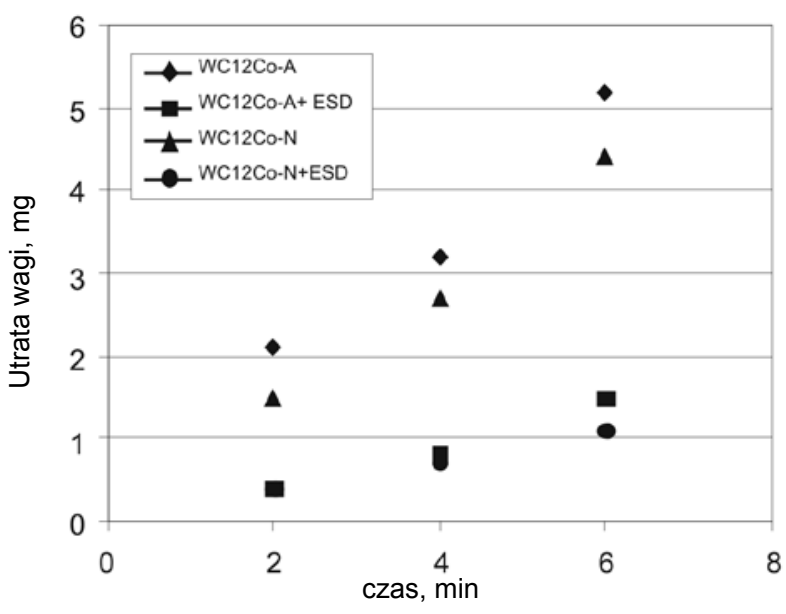

Rys. 7. Zużycie ścierne natryskiwanych naddźwiękowo powłok WC-12Co przed i po obróbce elektroiskrowej

Fig. 7. Abrasive wear of ultrasonically sprayed WC-12Co coatings before and after electro-spark discharge machining

WC i obecność w powłoce niewielkiej ilości czystego wolframu. Utworzona na powierzchni utworzonej powłoki w wyniku obróbki elektroiskrowej warstwa ma bardziej złożony skład fazowy. W przypadku powłoki nanostrukturalnej pojawia się, oprócz fazy WC, nowa faza $\mathrm{Co}_{2} \mathrm{~W}_{4} \mathrm{C}$ oraz niewielka ilość fazy $\mathrm{Co}_{2} \mathrm{C}$. W warstwie utworzonej na powłoce konwencjonalnej oprócz fazy WC występuje również intensywna faza $W_{2} C$ oraz niewielka obecność fazy $\mathrm{Co}_{3} \mathrm{~W}_{10} \mathrm{C}_{3}$. Nowe fazy w warstwie nałożonej elektrodą WC8Co to rezultat występowania lokalnie bardzo wysokiej temperatury sięgającej $(5 \div 40) 10^{3} \mathrm{~K}$, co powoduje dekompozycję materiału powłoki oraz elektrody [9]. Występujące różnice $\mathrm{w}$ składzie fazowym utworzonych warstw będą przedmiotem dalszych badań.

Dla nanostrukturalnej powłoki WC-12Co po szlifowaniu współczynnik tarcia wyniósł 0,2 , a dla powłoki z warstwą ESD 0,62. Natomiast w przypadku konwencjonalnej powłoki WC-12Co wyniósł on 0,3 , a dla powłoki z warstwą ESD 0,58. Zmiany współczynnika tarcia są wynikiem zmiany mikrogeometrii współpracującej powierzchni ze stalową kulką. Niezależnie od składu utworzonej powłoki, nałożona na nią warstwa elektroiskrowa ma zbliżoną mikrotwardość, twardość i chropowatość, co powoduje, że współczynniki tarcia w obydwu przypadkach są zbliżone.

Wyniki badań zużycia ściernego nanostrukturalnych i konwencjonalnych powłok WC-12Co przed i po obróbce elektroiskrowej są przedstawione na rysunku 7 . Przed każdym testem próbki były myte w acetonie i następnie ważone na wadze elektronicznej $z$ dokładnością $\pm 0,1 \mathrm{mg}$. Na podstawie wyników badań można stwierdzić, że natryskiwane powłoki WC-12Co po obróbce elektroiskrowej wykazały mniejsze zużycie niż powłoki bez tej obróbki. Największą odporność na zużycie ma nanostrukturalna powłoka WC-12Co po obróbce ESD. 


\section{Wnioski}

W wyniku obróbki elektroiskrowej natryskiwanych naddźwiękowo powłok WC-12Co powstała jednorodna warstwa węglika wolframu z niewielką zawartością kobaltu.

Utworzona w wyniku procesu ESD warstwa ma inną mikrostrukturę oraz skład fazowy niż nałożono naddźwiękowo powłoka WC-12Co.

\section{Literatura}

[1] Niinobe K., Watanabe S., Itakura K., Sakoda N., Tajiri T.: Matsue and Kurashiki: Pack boronizing of HVOF-sprayed WC-Co coatings. International Thermal Spray Conference, Osaka 2004, s. 895-897.

[2] Yilbas B.S., Arif A.F.M., Gondal M.A.: HVOF coating and laser treatment: three-point bending tests. Journal of Materials Processing Tech. Vol.: 164-165, Complete, May 15, 2005 , s. 954-957.

[3] Kim J.H., Baik K.H., Seong B.G., Hwang S.Y.: The influence of post heat-treatment on the wear properties of nano-structured WC-Co coatings. International Thermal Spray Conference, Basel 2005, s. 494-497.

[4] Yuan Jianhui, Zhu Yingchun, Zheng Xuebing, Ruan Qichao, Ji Heng: Improvement in tribological properties of atmospheric plasma-sprayed WC-Co coating followed by $\mathrm{Cu}$ electrochemical impregnation. Applied Surface Science Vol.: 255, Issue: 18, June 30, 2009, s. 7959-7965.
Nałożona warstwa ESD jest dobrze związana z powłoką, o czym świadczy stopniowa zmiana zawartości składników powłoki i warstwy.

Współczynnik tarcia w obydwu przypadkach natryskiwanych powłok węglikowych z warstwą ESD jest zbliżony, ponieważ jej skład, mikrostruktura, twardość i chropowatość są podane.

Nanostrukturalna powłoka WC-12Co po obróbce elektroiskrowej wykazała największą odporność na zużycie ścierne.

[5] Mindivan Harun: Wear behavior of plasma and HVOF sprayed WC-12Co+6\% ETFE coatings on AA2024-T6 aluminium alloy. Surface \& Coatings Technology Vol.: 204, Issue: 12-13, March 15, 2010, s. 1870-1874.

[6] Kim J.H., Baik K.H., Seong B.G., Hwang S.Y.: Effects of post-spraying heat treatment on wear resistance of WC-Co nanocomposite coatings. Materials Science and Engineering $A$ 449-451 (2007). s. 876-879.

[7] Ahmed R., Stewart S., Stoica V., Itsukaichi T.: Influence of post-treatment on the tribo-mechanical properties of cermet coatings. International Thermal Spray Conference, Osaka 2004, s. 912 -917.

[8] Żórawski W., Burakowski T.: Mikrostruktura nanostrukturalnych powłok węglikowych natryskanych naddźwiękowo. Inżynieria Materiałowa 6/2008, s. 608-610.

[9] Liu J., Wang R., Qian Y.: The formation of a single-pulse electrospark deposition spot, Surface \& Coatings Technology, 200, 2005, s. 2433-2437.

\section{Naukowo-Techniczna Konferencja Spawalnicza pt.: OSIĄGNIĘCIA - POTRZEBY - WYZWANIA}

Organizowana przez Instytut Spawalnictwa konferencja odbędzie się w dniach 16-18 października 2012 r. równocześnie z Międzynarodowymi Targami Spawalniczymi ExpoWELDING 2012 na terenie Centrum Targowo-Wystawienniczego Expo Silesia w Sosnowcu.

Konferencja i targi spawalnicze są najważniejszym polskim wydarzeniem branży spawalniczej tego roku. W trzydniowej konferencji wezmą udział specjaliści, naukowcy i praktycy w dziedzinie spawalnictwa i technologii pokrewnych. Podczas konferencji wygłoszonych zostanie 25 referatów, w tym 11 zagranicznych, poświęconych zarówno spawaniu nowoczesnych materiałów, jak i monitoringowi procesów łączenia, modelowaniu cyfrowemu oraz ocenie stanu spawalnictwa dziś i prognozom na przyszłość. Konferencja jest okazją do pozyskania nowej wiedzy, ale także umożliwia spotkanie specjalistów z branży i wymianę doświadczeń. Uczestnicy konferencji będą mogli codziennie odwiedzać stoiska wystawców targów ExpoWELDING 2012.

Zgłoszenia na konferencję są przyjmowane do 14 września:

\section{Komitet Organizacyjny}

54. Naukowo-Technicznej Konferencji Spawalniczej Instytut Spawalnictwa

ul. Bł. Czesława 16-18, 44-100 Gliwice

tel.: 322310011 w. 367, 222, 395

fax: 32 231-46-52, 32 331-61-05

e-mail: is@is.gliwice.pl, market@is.gliwice.pl

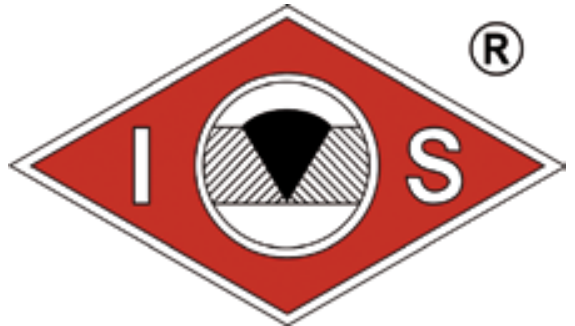

R.

Program konferencji i warunki uczestnictwa są zamieszczone na stronie: www.konferencja.is.gliwice.pl 